\title{
JUSFEMINISMO E LITERATURA: A MULHER TRABALHADORA EM BRECHT ${ }^{1}$
}

\section{JUSFEMINISM AND LITERATURE: THE WORKING WOMAN IN BRECHT}

\author{
Kelly Helena Santos Caldas² \\ Míriam Coutinho de Faria Alves ${ }^{3}$ \\ Tâmis Hora Batista Fontes Couvre ${ }^{4}$
}

RESUMO: O presente trabalho tem como premissa estrutural e metodológica a relação interdisciplinar entre direito, literatura e teatro. Através da obra do dramaturgo, diretor e escritor alemão Bertold Brecht, especificamente, da peça $A$ Santa Joana dos Matadouros, serão articuladas abordagens jusfeministas para pensar a mulher trabalhadora. Por meio da fenomenologia-existencial, o direito é aqui pensado em sua narratividade, intertextualidade e intersubjetividade, não como um fim em si mesmo, mas como uma dinâmica dialética e histórica de relações humanas. A arte é para Brecht um espaço científico (PEIXOTO, 1974), assim como os estudos em direito e literatura são caminhos humanistas de encontro com o outro (GONZALEZ, 2016). Este lugar de alteridade coloca o leitor-espectador ao lado da Joana Dark brasileira, por meio do reconhecimento crítico do modo de produção capitalista e da divisão sexual do trabalho. A desigualdade entre homens e mulheres no mercado de trabalho é uma fratura exposta, onde ao homem cabe o prestigio e a produtividade e à mulher a exaustão, a inferioridade e a mera reprodutividade (CISNE, 2015).

PALAVRAS-CHAVE: Bertold Brecht; estética jusliterária; mulher trabalhadora; capitalismo; divisão sexual do trabalho.

ABSTRACT: The present work has as structural and methodological premise the interdisciplinary relationship between law, literature and theater. Through the work of the German playwright, director and writer Bertold Brecht, specifically, of the play A Santa Joana dos Matadouros, jusfeminist approaches to thinking working women will be articulated. Through existential phenomenology, the right is thought here of its nartivity, intertextuality and intersubjectivity, not as an end in itself, but as a dialectical and historical dynamics of human relations. Art

1 Artigo recebido em 17/03/2020 e aceito para publicação em 05/06/2020.

2 Mestranda em Direito (UFS). E-mail: kellycaldas.contato@gmail.com. ORCID: https://orcid. org/0000-0001-6453-8334. ResearcherID: ABG-2288-2020.

${ }^{3}$ Professora do Departamento de Direito (UFS). Doutora em Direito (UFBA).E-mail. Miriamfaria2002@ yahoo.com.br. ORCID: https://orcid.org/0000-0003-1701-3652. ResearcherID: ABG-2534-2020.

${ }^{4}$ Mestranda em Direito (UFS). E-mail: tamis.hora@gmail.com. ORCID: https://orcid.org/00000002-7996-4237. ResearcherID: ABG-2279-2020.

Interdisciplinar, Sầo Cristóvầo, UFS, v. 33, jan-jun, p. 201-217, 2020

D0I: https://doi.org/10.47250/intrell.v33i1.14950 
Kelly Helena Santos Caldas; Míriam Coutinho de Faria Alves;

Tâmis Hora Batista Fontes Couvre

is for Brecht a scientific space (PEIXOTO, 1974), as well as studies in law and literature are humanist paths of encounter with each other (GONZALEZ, 2016). This place of otherness places the reader-spectator next to the Brazilian Joana Dark, through the critical recognition of the capitalist mode of production and the sexual division of labor. Inequality between men and women in the labor market is an exposed fracture, where men are prestigious and productive and women are responsible for exhaustion, inferiority and mere reproductivity (CISNE, 2015). KEYWORDS: Bertold Brecht; jusliterária aesthetics; working women; capitalism; sexual division of labour.

\section{Introduçăo}

O presente trabalho pretende lançar um olhar jusfeminista diante da realidade laboral da mulher trabalhadora brasileira, através da peça A Santa Joana dos Matadouros, do dramaturgo, diretor e escritor alemão Bertold Brecht. Primeiramente, serão apresentadas notas biográficas e teóricas sobre o teatro épico e a dramaturgia de Bertold Brecht, já que se trata de um importante artista, crítico e criador do século XX (PEIXOTO, 1974).

O tópico seguinte trará, então, a análise da peça $A$ Santa Joana dos Matadouros, escrita por Brecht entre 1929 e 1931. A dramaturgia se passa, intencionalmente, na Grande Depressão dos Estados Unidos, em 1929, e a protagonista chama-se Joana Dark, não por acaso. Assim como a Joana Darc francesa, a Joana Dark americana é uma mulher comum que rompe o espaço demarcado pela sociedade patriarcal e ousa ocupar o espaço público, em busca de justiça e igualdade.

Ao conhecer o chão de fábrica, as lutas do movimento sindical e a injustiça vivida pelos trabalhadores, Joana Dark descobre os detalhes cruéis do mundo hostil do trabalho desumanizado e precário. A jornada e os conflitos vividos pela protagonista reforçam a interdisciplinaridade entre direito, literatura e teatro, pois convoca o leitor a se posicionar para além da obra literária.

Por meio do método qualitativo fenomenológico e da epistemologia crítica, pensa-se a arte como uma experiência de fruição intelectual e profundamente humana. O conhecimento jusliterário e jusfeminista aqui apresentado é vivencial, dialógico, circular e não hermético. A análise das narrativas jurídicas apon- 
tadas neste trabalho surgem como consequência relacional da literatura brechtiana.

O modo de produção capitalista e a divisão sexual do trabalho, vivenciada na peça de Brecht, provocam a reflexão sobre a vida da Joana Dark brasileira, que também enfrenta jornadas exaustivas, inferiorizadas, mal remuneradas e invisibilizadas. Ocorre que, na realidade brasileira colonizada, subdesenvolvida e terceiro-mundista, as relações trabalhistas são demarcadas por índices altos de informalidade e subempregos, sob o falacioso argumento de que direitos trabalhistas oneram e criam obstáculos desproporcionais ao desenvolvimento empresarial do país.

O tópico subsequente traçará, portanto, uma perspectiva jusfeminista do mercado de trabalho, ao evidenciar a ineficácia do Estado de Bem-Estar Social e do Estado Democrático de Direito. Com o neoliberalismo, o desmonte dos direitos trabalhistas (DELGADO, 2015), sendo o direito do trabalho ainda mais precário quando se trata da mulher trabalhadora, detentora dos maiores índices de desocupação, informalidade e dos menores rendimentos salariais. Os conceitos de subordinação e precarização do trabalho feminino serão abordados com base nos ensinamentos de Perrot (2017), Mirla Cisne (2015), Ricardo Antunes (2009), acerca das opressões de gênero que demarcam a divisão sexual do trabalho.

Também será destacado, nesse estudo, a regulamentação trabalhista tardia do(a) empregado(a) doméstico(a), exercício realizado historicamente por mulheres, e predominantemente por mulheres pretas, além do posicionamento da Corte Suprema brasileira (STF) sobre a reforma trabalhista e a tentativa de flexibilização dos direitos da mulher gestante no ambiente laboral. Ao final, fundamenta-se o caminho interdisciplinar do Direito e Literatura, com os ensinamentos de Henriete Karam (2017); Calvo González (2016); Warat (2004; 1997), dentre outros, a fim de repensar o Direito e assegurar a dignidade das mulheres frente ao mercado de trabalho patriarcal, desigual e capitalista.

\section{Bertold Brecht em cena}

Bertold Brecht foi um escritor, poeta, diretor teatral e dramaturgo alemão de importância marcante para o pensamento crítico e literário do século XX. Nascido em Augsburg, em uma 
família burguesa, desde cedo criticou as instituições rígidas e as contradições do capitalismo. Atento aos movimentos artísticos do seu tempo dedicou-se à dramaturgia e à poesia. "Brecht, através do historicismo, aprofunda o conhecimento desta sociedade, penetrando em suas contradições mais graves, criticando-a 'de dentro': a arte torna-se ciência." (PEIXOTO, 1974, p. 32).

Com a segunda guerra mundial e a propagação do regime totalitário nazista, Brecht e sua família passam a viver em exílio. Espectador ativo da vida política autoritária e da violência cruenta dela originada, a literatura teatral ${ }^{5}$ de Brecht foi povoada por discussões éticas, estéticas dialéticas e históricas. Privilégios sociais, opressões, dominação, desigualdade, bondade, capital, lucro, ganância, guerra, miséria, utilitarismo e exploração foram temas centrais nas relações, circunstâncias, enredos, protagonistas e antagonistas. Em Brecht, não existe a figura do vilão e do herói, o que há são sujeitos em conflito diante das pressões que a estrutura social lhes impõe.

Sua obra é queimada no governo Hitler, exatamente por contestar as bases nefastas do nazismo. Um teatro político e instigante de um pensar crítico por meio do público, um teatro capaz de questionar o espectador ao invés de inebriá-lo com a ficcionalidade. Para Sérgio de Carvalho, diretor do grupo teatral A Companhia do Latão:

\begin{abstract}
O estilo de Brecht - como viemos a perceber depois - apresenta a desumanização como um processo realizado por homens. Como um processo diante do qual é possível fazer algo. Um processo, portanto, que se objetiva com a colaboração do público. Mas, para isso precisa ser explicitado na própria forma de representar. Brecht nos ensina a pesquisar formas de concretizar negativamente o processo social de coisificação. Ele procura uma atitude de inteligibilidade, sem facilitações, em relação a um mundo confuso. Uma lição fora de moda, num tempo em que os artistas cultuam o incompreensível. (CARVALHO, 2009, p. 16, grifo nosso).
\end{abstract}

51956 foi o ano em que a primeira peça de Bertold Brecht, A Exceção e A Regra, foi encenada no Brasil, precisamente na Escola de Arte Dramática, localizada em São Paulo. Em âmbito profissional, a primeira encenação aconteceu em 1958, no Teatro Maria Della Costa, com a peça A Alma Boa de Setsuan, seguida de Os Fuzis da Senhora Carrar, encenada pelo Teatro de Arena em 1962, o Círculo de Giz Caucasiano, encenação do Teatro Nacional de Comédia no ano seguinte, e A Ópera dos Três Vinténs, no Teatro Ruth Escobar, em 1964. (ENCICLOPÉDIA Itaú Cultural de Arte e Cultura Brasileira, 2020). 
Para Bertold Brecht, a dramaturgia teatral é uma "arma de conscientização e politização" (PEIXOTO, 1974, p. 13). A arte é vista por ele como um uma arena de aprendizado social, um espaço didático capaz de tornar o espectador em um sujeito crítico e conhecedor das tensões e discursos estruturais que lhe são apresentados como falsas conjunturas naturais e imutáveis. Roubine (2003) destaca a fragmentariedade das cenas, a revelação do cenário e dos atores por trás do figurino e das luzes e a relação desapaixonada do texto com o espectador como elementos que caracterizam o teatro épico e o diferenciam do teatro aristotélico.

O teatro épico é "'um palco científico' capaz de esclarecer o público sobre a sociedade e a necessidade de transformá-la; capaz ao mesmo tempo de ativar o público, de nele suscitar a ação transformadora" (ROSENFELD, 2014, p. 148). Enquanto o teatro dramático valoriza os sentimentos, o teatro épico prioriza a racionalidade; enquanto o teatro dramático apresenta ao espectador uma realidade imutável e inevitável, o teatro épico recoloca as perspectivas da cena nas mãos do espectador, fazendo ao enredo o contexto processual, no qual o público compreenderá as mudanças sociais, tanto na ordem pessoal quanto na ordem coletiva.

O didatismo, a estranheza e o distanciamento são elementos linguísticos e estéticos elementares para o teatro épico e para o protagonismo ativo do espectador, que esta forma de dramaturgia e ação cênica propõe. Em Diário de Trabalho - Volume I, Brecht apresenta os procedimentos para se alcançar o distanciamento:

Para conseguir o efeito-d o ator deve abandonar sua total conversão ao personagem do palco. $\mathrm{O}$ ator mostra o personagem, cita suas falas, repete um incidente da vida real. A plateia não é totalmente "arrebatada"; não precisa amoldar-se psicologicamente, adotar uma atitude fatalista para com o destino representado. (Pode sentir raiva onde o personagem sente alegria etc. Está livre para - e às vezes é até encorajada a - imaginar um outro curso dos acontecimentos, ou tentar encontrar um, e assim por diante.) Os incidentes são historicizados e socialmente ambientados. (o primeiro caso, naturalmente, ocorre acima de tudo com os incidentes dos dias atuais: o que quer que seja não foi sempre, e não o será sempre. O segundo 
reiteradamente projeta uma luz controversa sobre a ordem social reinante e sujeita-a a discussão). (BRECHT, 2002, p. 101).

A dramaturgia brechtiana está muito mais preocupada com os rumos da sociedade e com a capacidade pedagógica do texto e da atuação do que com a ludicidade, a catarse e as emoções. A arte existe não como utilidade a serviço do poder dominante, e sim como um lugar de aprendizagem, de questionamento das desigualdades, de perguntas críticas, de descoberta dos agentes sociais que determinam as escolhas dos cidadãos comuns, de luta de classes e, principalmente, de alteridade.

\section{Peça: A santa Joana dos Matadouros}

A Santa Joana dos Matadouros, escrita por Brecht entre 1929 e 1931, é um retrato interessante da forma épica de pensar a dramaturgia. A realidade religiosa e a realidade socioeconômica são bem colocadas, pelo autor, no enredo. A obra se passa, intencionalmente, na Grande Depressão dos Estados Unidos, em 1929 - grande crise do capitalismo, até então. Joana Dark é a protagonista, tenente de um grupo missionário que oferece alimentos para os operários em condução de miséria, já que, diante da queda da Bolsa de Valores de Wall Street, os trabalhadores dos frigoríficos de Chicago são demitidos arbitrariamente ou mantidos em condições desumanas e precarizadas, e com baixíssimos salários.

Os industriais vivem num clima de terror e sangue, enquanto os operários, jogados no mais brutal desemprego, o que significa miséria e fome, organizam a incontrolável revolta. A religião personificada no Exército da Salvação (na peça intitulado "Chapéus de Palha Pretos"), intervém na batalha de classes procurando atenuar as contradições, enganar o povo com as promessas da felicidade eterna após a morte. (PEIХОTO, 1974, p. 137-138).

A escolha do nome da protagonista também não foi uma coincidência histórica, ao contrário, trata-se de uma paródia intencional do autor. Tanto a Joana Dark americana quanto a Joana Darc 
francesa são mulheres, cujo espaço mítico e santificado da fé cristã encontra destaque e negação. Ao ousar ocupar o espaço público, a Joana Darc francesa é considerada bruxa e condenada a morrer na fogueira, enquanto isso, a Joana Dark americana é expulsa do grupo missionário, sumariamente, e, por defender a classe trabaIhadora, é agredida por policiais e morre aos 25 anos de idade.

Snyder, o major dos Boinas Pretas, diz a Joana "devolva o seu uniforme e faça a sua mala! Saindo desta casa você leva essa gentinha que você nos trouxe. Você atraiu só gentinha e escória, e agora vai fazer parte dela. Vá buscar as suas coisas." (BRECHT, 2009, p. 103). Em poucas palavras, Joana é excluída do espaço religioso e lançada à violência do espaço público. $O$ caráter mutável do percurso épico é colocado no momento em que Joana passa a questionar o homem religioso, ao descobrir os males e as injustiças provenientes dos industriários da carne.

O capitalismo é revelado não de um lugar distanciado, mas, ao contrário, de um lugar narrativo e dialético. "Como pagarei a minha casinha tão arranjada e úmida, em que moram doze pessoas? Dezessete prestações estão pagas, mas faltando a última estamos na rua e nunca mais veremos o chão de terra batida [...]" (BRECHT, 2009, p. 32). Esta citação da obra retrata bem a condição degradante dos trabalhadores demitidos dos frigoríficos, tratados como objeto e reificados pelo capital.

O elemento épico da estranheza é perceptível na passagem em que um funcionário é sugado pelas máquinas e tem sua carne triturada, misturada a carne dos bois e enlatada para a venda. De uma crueza violenta, nesta cena Brecht quer chocar o espectador, quer tirá-lo da inércia e da passividade, quer lançá-lo à realidade como ela é. $O$ teatro épico revela a ficcionalidade dos direitos diante da perversa desigualdade entre os humanos, e por meio desta identificação crítica, o espectador acessa o outro. "A estranheza é um novo estado, que implica que o outro se nos imiscua, participe de nós, internalize-nos e, por tudo isso, também interfira em nós. É isso a outridade." (GONZALEZ, 2016, p. 135).

A trajetória de Joana Dark é, ao mesmo tempo, um processo didático e científico. Trata-se de uma mulher comum que rompe o espaço para ela demarcado pela sociedade patriarcal e religiosa, ou seja, uma mulher em transformação social. Joana Dark ao conhecer o chão de fábrica, as lutas do movimento sindi-

Interdisciplinar, Săo Cristóvằo, UFS, v. 33, jan-jun, p. 201-217, 2020 D0I: https://doi.org/10.47250/intrell.v33il.14950 
Kelly Helena Santos Caldas; Míriam Coutinho de Faria Alves; Tâmis Hora Batista Fontes Couvre

cal e a injustiça vivida pelos trabalhadores se torna uma mulher trabalhadora. Mesmo sem nenhum vínculo empregatício ou relação jurídica com as fábricas de carne, Joana ousa ocupar o espaço público e político do trabalho. Por ironia épica, o lugar dos matadouros, se transforma, paradoxalmente, em um lugar de vida, ou ao menos, tentativa de vida.

A tomada de consciência da protagonista é perceptível nesta passagem da peça:

Joana: Olho este sistema, por fora. É meu velho conhecido, o funcionamento é que eu não via! Alguns poucos em cima outros muitos em baixo, e os de cima chamando os de baixo: venham para o alto, para que todos estejam em cima, mas olhando melhor você vê algo de encoberto entre os de cima e os de baixo. Algo que parece uma pinguela, mas não é. E agora você vê perfeitamente que a tábua é uma gangorra, este sistema todo é uma gangorra cujas extremidades são relativas uma à outra, os de cima estão lá só porque e enquanto os demais estão embaixo. E já não estariam em cima se acaso os outros, deixando o seu lugar, subissem, de sorte que necessariamente os de cima desejam que os de baixo não subam e fiquem embaixo para sempre. É necessário também que os de baixo sejam em número maior que os de cima, para que estes não desçam. Senão não seria uma gangorra. (BRECHT, 2009, p. 139).

O desfecho de $A$ Santa Joana dos Matadouros não poderia ser mais crítico e provocativo. $O$ fato de Joana se tornar uma muIher trabalhadora e uma defensora dos direitos fundamentais dos trabalhadores não a coloca, em nenhum momento da peça, em posição de heroísmo ou vitória. Em sentido oposto, à medida que a protagonista passa a enxergar a realidade socioeconômica e a tentar interver neste sistema pautado pelo capital, o seu corpo é agredido pela fome, pelo frio e pela violência policial. A subalternidade e o silenciamento chegam ao seu ápice com o coro masculino que abafa a voz de Joana, em seu leito de morte.

A definição da morte de Joana Dark representa, com nitidez, quem narra a história das mulheres. Com o falecimento da protagonista, sua memória é deturpada e recriada pelo major do 
grupo religioso. Na versão de Snyder: "Joana Dark, vinte e cinco anos de idade, derrubada pela pneumonia ao defender a palavra de Deus nos matadouros de Chicago, combatente e mártir!" (BRECHT, 2009, p. 189).

A mordaça sufocante colocada, simbolicamente, em Joana Dark é a representação da mordaça estrutural lançada as mulheres que romperam com a santidade castradora da mulher dentro da ideologia patriarcal. "O poder de representar é um importante instrumento ideológico que possibilita descrever e controlar o modo como os Outros são percebidos, seja no coIonialismo [...], ou no patriarcalismo, nas relações de gênero." (JARDIM; CAVAS, 2017, p. 77).

O nosso olhar enquanto mulheres, nordestinas, juristas e leitoras nos convoca a problematização da Joana Dark brasileira, na busca por compreender os enfrentamentos vivenciados, em terra Brasilis, com relação à divisão sexual do trabalho. A concepção jusliterária será substancial para aproximar Bertold Brecht da contemporaneidade decolonial, com suporte nas teorias feministas e nas críticas do direito do trabalho ao capitalismo. "No meio do 'fogo cruzado' das concepções a favor e contra a liberdade do leitor, apresentamos uma formação crítica que valoriza a identificação das tensões sociais que envolvem aspectos sociais da violência contra a mulher." (GOMES, 2015, p. 279-280).

No mesmo sentido proposto por Iser (1979), as interpretações feitas a seguir se enquadram em um protagonismo do leitor ao recepcionar uma obra literária. A relação autor, texto e leitor não é fechada e única, ao contrário, a visão de mundo de quem recebe a obra é capaz de criar percepções antes inexistentes e impensáveis pelo autor, ampliando as possibilidades performativas e discursivas com a literatura.

\section{Abordagem jusfeminista da mulher trabalhadora}

O modo de produção capitalista apaga o homem por trás do trabalhador e a mulher por trás da trabalhadora. Desumanizados como objetos descartáveis, os trabalhadores e trabalhadoras vivenciaram e vivenciam a precarização da força de trabalho. Na realidade brasileira colonizada, subdesenvolvida e terceiro-mundista, as relações trabalhistas são demarcadas por índices altos 
Kelly Helena Santos Caldas; Míriam Coutinho de Faria Alves;

Tâmis Hora Batista Fontes Couvre

de informalidade ${ }^{6}$, sob o falacioso argumento de que direitos trabalhistas oneram e criam obstáculos desproporcionais ao desenvolvimento empresarial do país. Em Direito Fundamental ao Trabalho, Gabriela Neves Delgado faz uma relação certeira entre o neoliberalismo e a redução de direitos trabalhistas:

\begin{abstract}
Diante da conjuntura econômica gerida no contexto neoliberal, propagou-se o discurso de que o Direito do Trabalho constitui verdadeiro obstáculo à evolução da economia e ao rebaixamento do preço da força de trabalho, surgindo necessidade, pois, de sua reformulação. Assim, o Direito do Trabalho passou a inserir, em sua estrutura e dinâmica, fenômenos típicos do neoliberalismo, com destaque para a desregulamentação e a flexibilização de direitos. (DELGADO, 2015, p. 172).
\end{abstract}

A ineficácia do Estado de Bem-Estar Social e do Estado Democrático de Direito se aprofundam no direito do trabalho, principalmente em relação à mulher trabalhadora, que possui maior índice de desocupação, informalidade e baixo rendimento salarial. E para compreender a subordinação e a precarização do trabalho feminino é preciso observar as opressões de gênero que demarcam a divisão sexual do trabalho. Perrot (2017), em Os excluidos da história: operários, mulheres e prisioneiros, destaca a atuação patriarcal da clausura da mulher no espaço doméstico do lar, do cuidado e da maternidade solitária, quando ao homem sempre foi concedido o espaço do poder, da política, da economia e da produção.

Mirla Cisne, na obra Feminismo e consciência de classe no Brasil, ressalta que a divisão sexual do trabalho coloca o homem na função produtiva e relega à mulher a função reprodutiva, escancarando a desigualdade entre homens e mulheres. A divisão sexual do trabalho é "a base das assimetrias e hierarquias contidas nessa divisão, e que se expressam nas desigualdades existentes, dentre outros aspectos, nas carreiras, nas qualificações e nos salários entre os sexos." (CISNE, 2015, p. 74).

\footnotetext{
6 “Em 2019, a informalidade - soma dos trabalhadores sem carteira, trabalhadores domésticos sem carteira, empregador sem CNPJ, conta própria sem CNPJ e trabalhador familiar auxiliar - atingiu $41,1 \%$ da população ocupada, o equivalente a 38,4 milhões de pessoas." Dados da Pesquisa Nacional por Amostra de Domicílios Contínua (PNAD Contínua), divulgados pelo Instituto Brasileiro de Geografia e Estatística (IBGE). Disponível em: Desemprego cai para 11,9\% na média de 2019; informalidade é a maior em 4 anos | Agência de Notícias | IBGE.
}

Interdisciplinar, Săo Cristóvăo, UFS, v. 33, jan-jun, p. 201-217, 2020 D0I: https://doi.org/10.47250/intrell.v33i1.14950 
Ricardo Antunes, ao escrever Os Sentidos do Trabalho, observa que a desigualdade salarial atravessa o trabalho feminino, na medida em que aos homens o capital intensivo e às mulheres o trabalho intensivo, inferior, desqualificado e de menor importância. Jornadas prolongadas e acumulação, cansativa e permanente, do trabalho doméstico e do trabalho fabril, na encruzilhada interseccional que liga a opressão de gênero a opressão de classe.

A mulher trabalhadora, em geral, realiza sua atividade de trabalho duplamente, dentro e fora de casa, ou, se quisermos, dentro e fora da fábrica. E, ao fazê-lo, além da duplicidade do ato do trabalho, ela é duplamente explorada pelo capital: desde logo por exercer, no espaço público, seu trabalho produtivo no âmbito fabril. Mas, no universo da vida privada, ela consome horas decisivas no trabalho doméstico, com o que possibilita (ao mesmo capital) a sua reprodução, nessa esfera do trabalho não diretamente mercantil, em que se criam as condições indispensáveis para a reprodução da força de trabalho de seus maridos, fiIhos/as e de si própria. (ANTUNES, 2009, p. 108).

Diante deste cenário de ausências estruturais, o direito do trabalho, por vezes, perpetua a opressão da mulher trabalhadora. A proteção do trabalho feminino é demarcada por muros de invisibilidade. Licença maternidade e estabilidade da gestante são consideradas, por muitos empresários, como "gastos" excessivos e desnecessários, a encarecer e impossibilitar a contratação das mulheres.

A regulamentação dos direitos trabalhistas do(a) empregado(a) doméstico(a), exercício realizado historicamente por muIheres, com destaque para a predominância de mulheres pretas, é, também, um exemplo do atraso jurídico e da insuficiência das normas formais para mudar realidades sociais opressoras. A regulamentação deste trabalho feminino se deu apenas em 2015, com a Lei Complementar no 150, todavia a irregularidade e a informalidade deste ofício continuam a acontecer em muitas casas brasileiras.

Sobre o trabalho das gestantes e lactantes em ambientes insalubres, convoca-se a análise da mudança normativa da Reforma Trabalhista (Lei 13.467/17). Pelo novo texto do art. 394-A da Consolidação das Leis Trabalhistas, as mulheres deveriam continuar o labor, mesmo que em atividade insalubre, com risco leve e

Interdisciplinar, Sằo Cristóvầo, UFS, v. 33, jan-jun, p. 201-217, 2020 D0l: https://doi.org/10.47250/intrell.v33i1.14950 
Kelly Helena Santos Caldas; Míriam Coutinho de Faria Alves; Tâmis Hora Batista Fontes Couvre

médio. Somente em se tratando de insalubridade máxima, caberia à empresa alocar a mulher trabalhadora noutro espaço salubre. Tal medida, claramente, prejudicial à dignidade das gestantes e lactantes foi apreciada pelo Supremo Tribunal Federal, por meio da Ação Direta de Inconstitucionalidade (ADIN 5938).

Por maioria de votos, o STF entendeu que o art. 394-A, incisos II e III, dispositivos incorporados pela Reforma Trabalhista, eram inconstitucionais. Com relatoria do Ministro Alexandre de Morais, em 29/05/2019, em Tribunal Pleno, a proteção constitucional da maternidade da mulher trabalhadora prevaleceu. Merece transcrição a ementa da decisão:

Ementa: DIREITOS SOCIAIS. REFORMA TRABALHISTA. PROTEÇÃO CONSTITUCIONAL À MATERNIDADE. PROTEÇÃO DO MERCADO DE TRABALHO DA MULHER. DIREITO À SEGURANÇA NO EMPREGO. DIREITO À VIDA E À SAÚDE DA CRIANÇA. GARANTIA CONTRA A EXPOSIÇÃO DE GESTANTES E LACTANTES A ATIVIDADES INSALUBRES. 1. O conjunto dos Direitos sociais foi consagrado constitucionalmente como uma das espécies de direitos fundamentais, caracterizando-se como verdadeiras liberdades positivas, de observância obrigatória em um Estado Social de Direito, tendo por finalidade a melhoria das condições de vida aos hipossuficientes, visando à concretização da igualdade social, e são consagrados como fundamentos do Estado Democrático, pelo art. 1ㅇ, IV, da Constituição Federal. 2. A Constituição Federal proclama importantes direitos em seu artigo 60, entre eles a proteção à maternidade, que é a ratio para inúmeros outros direitos sociais instrumentais, tais como a licença-gestante e o direito à segurança no emprego, a proteção do mercado de trabalho da mulher, mediante incentivos específicos, nos termos da lei, e redução dos riscos inerentes ao trabalho, por meio de normas de saúde, higiene e segurança. 3. A proteção contra a exposição da gestante e lactante a atividades insalubres caracteriza-se como importante direito social instrumental protetivo tanto da mulher quanto da criança, tratando-se de normas de salvaguarda dos direitos sociais da mulher e de efetivação de integral proteção ao recém-nascido, possibilitando seu pleno desenvolvimento, de maneira harmônica, segura e

Interdisciplinar, Săo Cristóvăo, UFS, v. 33, jan-jun, p. 201-217, 2020 D0I: https://doi.org/10.47250/intrell.v33i1.14950 212 
sem riscos decorrentes da exposição a ambiente insalubre (CF, art. 227). 4. A proteção à maternidade e a integral proteção à criança são direitos irrenunciáveis e não podem ser afastados pelo desconhecimento, impossibilidade ou a própria negligência da gestante ou lactante em apresentar um atestado médico, sob pena de prejudicá-la e prejudicar o recém-nascido. 5. Ação Direta julgada procedente. (BRASIL, 2019, p. 1-2, grifo nosso).

A Reforma Trabalhista de 2017 traz a fragilidade de direitos da mulher trabalhadora para o centro da discussão, traz o sentimento de que, até as garantias mais básicas e protetivas ao protagonismo feminino no mercado de trabalho podem ser suplantadas. O exercício do trabalho digno e a certeza de um ambiente de trabalho equilibrado, condições mínimas de dignidade laboral, são negadas, não só às mulheres grávidas e lactantes. Para a ruptura de privilégios discursivos e normativos no âmbito trabalhista, é preciso desvelar as explorações e as opressões de gênero, tão estruturantes do modo de produção capitalista.

Repensar o Direito brasileiro é necessário, sobretudo na contemporaneidade, marcada pelos desafios da instituição do Estado Democrático, pelos avanços biotecnológicos, pela globalização e pelo, consequente, declínio do positivismo. Para tanto, a Arte se mostra como aporte humanizador, que traz ao Direito uma abertura de sentidos que permite a efetiva defesa dos direitos humanos. Nesse sentido, ensina Henriete Karam:

\footnotetext{
Com o declínio do positivismo jurídico e os desafios impostos pela instituição do Estado democrático de direito, em especial no que se refere à defesa dos direitos fundamentais, o movimento Direito e Literatura inaugura um peculiar e promissor campo interdisciplinar que oferece novas possibilidades de compreensão tanto da natureza humana e dos conflitos sociais quanto dos impasses e desafios que o direito enfrenta na contemporaneidade. (2017, p. 828).
}

A partir da peça Santa Joana dos matadouros, é possível não só refletir sobre a vida e as vozes femininas, no mercado de trabalho, mas, principalmente, colocar-se no lugar dessas muIheres, no lugar no outro, no lugar daquele que sofre a violência

Interdisciplinar, Sằo Cristóvăo, UFS, v. 33, jan-jun, p. 201-217, 2020 D0I: https://doi.org/10.47250/intrell.v33i1.14950 
institucionalizada. Esse convite a sentir o que o outro sente é defendido por Calvo González (2016) como um convite para "sair ao outro", cujo sentido não quer dizer, simplesmente, colocar-se frente ao outro, mas colocar-se como outro frente a si mesmo (GONZALEZ, 2016, p. 133).

Cattoni de Oliveira propõe, inclusive, que "Só aquele que se coloca na perspectiva dos participantes envolvidos em questões jurídicas é capaz de adotar a postura hermenêutica adequada a compreender tais questões" (2009, p. 94). Assim, "a linguagem da Literatura, que, como a dos direitos, tem vocação universal" (GONZALEZ, 2016, p. 126) deve ser utilizada tanto na prática, quanto na formação jurídica, para ampliar a capacidade crítica dos intérpretes das leis.

Ao contrário, restringir a posição crítica do estudante e profissional do direito é uma prática pedagógica fadada ao fracasso, como há muito Luis Alberto Warat ${ }^{7}$ (2004) denunciava, acreditando que o sentido do ensino do direito estava na prática dos direitos humanos, dentro de um espaço político de debates ilimitados e indeterminados, "Porque se aprende o direito entregando suas certezas à morte" (WARAT, 2004, p. 382-383).

$O$ fato é que as verdades jurídicas precisam ser confrontadas, pois elas são demarcadas por vozes coloniais e construídas pelas epistemologias dominantes. Para Warat (1997) a razão instrumental do jurista conduz a perpetuação da forma totalitária de sociedade, ao apaixonamento cego, indiferente e desumanizado. Cabendo ao direito reencontrar a paixão, o sentir, o pulsar, a criatividade e o encontro com o outro. Os percursos jusliterários acabam por assumir este papel emancipatório, democrático, diverso e plural.

\section{Conclusồes finais}

A dramaturgia teatral de Bertold Brecht atravessou o norte global e chegou às experiências do terceiro mundo, experiências estas marcadas pelo colonialismo, pelo racismo, pelo sexismo, pela opressão e pela desigualdade estrutural. Não há como ana-

\footnotetext{
${ }^{7} \mathrm{O}$ autor defendia uma proposta existencial-pedagógica, com a postura subversiva do surrealismo e que busca "injetar um ponto de ato poético na educação e na pedagogia da idade digital" (WARAT, 2004, p. 407), chamando-a de "pedagogia do novo", a qual "tem que ensinar o prazer de viver, não verdades a consumir" (WARAT, 2004, p. 416).
} 
lisar o percurso de Joana Dark, na peça A Santa Joana dos Matadouros, sem pensar nos obstáculos enfrentados pela mulher trabalhadora europeia e americana e, também, brasileira.

A opressão de gênero privilegia o homem trabalhador em face da mulher trabalhadora, na qual a figura feminina é o sustentáculo para o funcionamento do modo de produção do próprio capital (CISNE, 2015). O lugar do doméstico, do castrado, do cuidado e da docilidade continua sendo imputado às mulheres, que acumulam as tarefas subalternas e mal remuneradas no mercado de trabalho, com as tarefas domésticas, sem qualquer salário, em suas casas, além da maternidade solo, enquanto aos homens é conferido o poder, a política, a força e os privilégios do patriarcado (PERROT, 2017).

Apesar de Brecht não apontar, de forma expressa, uma reflexão feminista da divisão sexual do trabalho, a leitura enquanto parte integrante da construção da própria obra permitiu um olhar jusfeminista da trajetória oprimida, violentada e silenciada de uma mulher que ousou ocupar o espaço público na luta pelos direitos trabalhistas e pela dignidade dos operários.

Com isso, conclui-se que a articulação interdisciplinar entre direito e literatura, entre teatro épico e atuação jurídica permite o desvelar dos conflitos, das rachaduras, do sangue e das cicatrizes da dominação colonial e patriarcal. A falsa neutralidade jurídica reforça discursos inquisitivos, marcados por subjetividades dita universais, todavia, dominantes.

\section{Referência}

ANTUNES, Ricardo Luis Coltro. Os Sentidos do Trabalho: ensaio sobre a afirmação e a negação do trabalho. São Paulo: Boitempo, 2009.

BRASIL. Lei Complementar no 150, de 10 de junho de 2015. Dispõe sobre o contrato de trabalho doméstico; altera as Leis no 8.212, de 24 de julho de 1991, no 8.213, de 24 de julho de 1991, e no 11.196, de 21 de novembro de 2005; revoga o inciso I do art. 3ำ da Lei no 8.009, de 29 de março de 1990, o art. 36 da Lei $n$ o 8.213, de 24 de julho de 1991, a Lei no 5.859, de 11 de dezembro de 1972, e o inciso VII do art. 12 da Lei no 9.250, de 26 de dezembro 1995; e dá outras providências. Disponível em: http://www.planalto.gov.br/ccivil_03/leis/ Icp/lcp150.htm. Acesso em 15 nov. 2020.

Interdisciplinar, Săo Cristóvăo, UFS, v. 33, jan-jun, p. 201-217, 2020 DOI: https://doi.org/10.47250/intrell.v33il.14950 
Kelly Helena Santos Caldas; Míriam Coutinho de Faria Alves; Tâmis Hora Batista Fontes Couvre

BRASIL. Lei 13.467, 13 de julho de 2017. Altera a Consolidação das Leis do Trabalho (CLT), aprovada pelo Decreto-Lei no 5.452, de 10 de maio de 1943, e as Leis $\mathrm{n}$ 으.619, de 3 de janeiro de 1974, 8.036, de 11 de maio de 1990, e 8.212, de 24 de julho de 1991, a fim de adequar a legislação às novas relações de trabalho. Disponível em: http://www.planalto.gov.br/ccivil_03/_ato20152018/2017/lei/l13467.htm. Acesso em: 15 nov. 2020.

BRASIL. SUPREMO TRIBUNAL FEDERAL. Ação Direta de Inconstitucionalidade no 5938/DF. Confederação Nacional dos Trabalhadores Metalúrgicos recorrente. Relatoria Alexandre de Morais. Julgamento em 29 de mai. 2019. Disponível em: http://redir.stf.jus.br/paginadorpub/paginador.jsp?docTP=TP\&docID=750927271. Acesso em: 14 maio 2020.

BRECHT, Bertold. Diário de Trabalho, volume 1: 1938-1941. Tradução de Reinaldo Guarany e José Laurenio de Melo. Rio de Janeiro: Rocco, 2002.

BRECHT, Bertold. A Santa Joana dos Matadouros. Tradução de Roberto Schwarz. São Paulo: Cosac Naif, 2009.

CALVO GONZALEZ, José. 'Sair ao outro': afetividade e justiça em Mineirinho, de Clarice Lispector. Anamorphosis, v. 2, n. 1, jan./jun. 2016. Disponível em: seer.rdl.org.br/index.php/anamps/article/download/220/pdf_1. Acesso em: 26 maio 2016.

CARVALHO, Sérgio de. Uma experiência com teatro dialético no Brasil. In: CARVALHO, Sérgio de (org.). Introdução ao teatro dialético: experimentos da Companhia do Latão. 1. ed. São Paulo: Expressão Popular; Companhia do Latão, 2009.

CATTONI DE OLIVEIRA, Marcelo Andrade. Ronald Dworkin: De que maneira o direito se assemelha à literatura? Revista da Faculdade Mineira de Direito, UFMG, Belo Horizonte, no 54, p. 91-118. jan./jun. 2009.

CISNE, Mirla. Feminismo e consciência de classe no Brasil. São Paulo: Cortez, 2015.

DELGADO, Gabriela Neves. Direito Fundamental ao Trabalho. 2. ed. São Paulo: LTr, 2015.

Desemprego cai para 11,9\% na média de 2019; informalidade é a maior em 4 anos. Agência de Notícias IBGE. Disponível em: https://agenciadenoticias. ibge.gov.br/agencia-noticias/2012-agencia-de-noticias/noticias/26741-desemprego-cai-para-11-9-na-media-de-2019-informalidade-e-a-maior-em-4-anos. Acesso em: 15 set 2020.

GOMES, Carlos Magno. Violência de gênero: estratégias para a formação do leitor. Revista Língua \& Literatura, v. 17, n. 30, p. 279-295, dez, 2015. Disponível

Interdisciplinar, Săo Cristóvằo, UFS, v. 33, jan-jun, p. 201-217, 2020 D0l: https://doi.org/10.47250/intrell.v33il.14950 216 
em: https://ri.ufs.br/bitstream/riufs/1885/1/ViolenciaGeneroFormacaoLeitor. pdf. Acesso em: 26 maio 2020.

ISER, Wolfgang. O jogo do texto. In: LIMA, Luiz Costa (Coord. e Tradução). A Literatura e o leitor: textos da estética da recepção. 2. ed. Rio de Janeiro: Paz e Terra, 1979.

JARDIM, Gabriel de Sena; CAVAS, Cláudio de São Thiago. Pós-colonialismo e feminismo decolonial: caminhos para uma compreensão anti-essencialista do mundo. Revista Ponto e Vírgula, São Paulo, n. 22, p. 73, 2017. Disponível em: https://revistas.pucsp.br/index.php/pontoevirgula/article/view/33335/24902. Acesso em: 26 set. 2020.

KARAM, Henriete. Questões teóricas e metodológicas do direito na literatura: um percurso analítico-interpretativo a partir do conto Suje-se gordo!, de Machado de Assis. In: Revista Direito GV, São Paulo, V. 13 no 827-865, 2017. ISSN 2317-6172. Disponível em: http://www.scielo.br/pdf/rdgv/v13n3/ 1808-2432-rdgv-13-03-0827.pdf Acesso em: 05 de dezembro de 2019.

PEIXOTO, Fernando. Brecht: Vida e Obra. 3. ed. Rio de Janeiro: Paz e Terra, 1974.

PERROT, Michelle. Os excluídos da história: operários, mulheres e prisioneiros. Rio de Janeiro: Paz e Terra, 2017.

ROSENFELD, Anatol. O teatro épico. 6. ed. São Paulo: Perspectiva, 2014.

ROUBINE, Jean-Jacques. Introdução às grandes teorias do teatro. Tradução de André Telles. Rio de Janeiro: Jorge Zahar Ed., 2003.

TEATRO Épico. In: ENCICLOPÉDIA Itaú Cultural de Arte e Cultura Brasileiras. São Paulo: Itaú Cultural, 2020. Disponível em: http://enciclopedia.itaucultural.org. br/termo617/teatro-epico. Acesso em: 22 abr. 2020. Verbete da Enciclopédia. ISBN: 978-85-7979-060-7.

WARAT, Luis Alberto. Introdução geral ao Direito I - Interpretação da lei: temas para uma reformulação. Porto Alegre: Sergio Antonio Fabris, 1994.

WARAT, Luis Alberto. Epistemologia e ensino jurídico: o sonho acabou. Vol. II. Florianópolis. Fundação Boiteux, 2004.

Interdisciplinar, Săo Cristóvăo, UFS, v. 33, jan-jun, p. 201-217, 2020 D0I: https://doi.org/10.47250/intrell.v33il.14950 